\title{
Influenza Cataclysm, 1918
}

\author{
David M. Morens, M.D. and Jeffery K. Taubenberger, M.D., Ph.D. \\ Office of the Director (D.M.M.) and the Viral Pathogenesis and Evolution Section, Laboratory of \\ Infectious Diseases (J.K.T.), National Institute of Allergy and Infectious Diseases, Bethesda, MD.
}

This year marks the centennial of a true pandemic cataclysm: an influenza pandemic that killed 50 million to 100 million people globally — arguably the single deadliest event in recorded human history. ${ }^{1}$ It is an event worth contemplating, since evidence suggests that another pandemic at least as severe may occur one day. ${ }^{2}$

In the beginning, nothing was visible. Somewhere in the world, an otherwise harmless enzootic gastroenteric virus of wild waterfowl (ducks and geese) apparently "host switched" into human beings and began causing respiratory infections. The virus caused a low rate of human mortality from pneumonia. It went undetected as it spread gradually around the globe, ${ }^{3}$ killing at a rate (about 1 to $2 \%$ ) that was invisible beneath the high background mortality rates of the era. But when the pandemic eventually began to grow exponentially, it caused unmistakable statistical upticks in metropolitan mortality (between July and October 1918) and then exploded.

In the United States, the virus visited towns in rapid succession, ultimately killing 675,000 Americans, a percentage of the population that would amount to 2.15 million people today. Everyone lost a family member, friend, classmate, or workmate. There were bodies stacked three deep in hospital corridors, corpses piled up at cemetery entrances, mass graves, and countless bewildered orphans. No one knew the cause. There were no specific treatments. ${ }^{3}$ Some people compared it to a biblical plague.

What happened? Biomedical scientists have spent a full century piecing together some answers. ${ }^{2,4}$ The epidemiologic patterns of the pandemic were well characterized during and after 1918. The causal influenza A virus was discovered in 1933, allowing seroepidemiologic studies that shed additional light on its origin. Between 1995 and 2005, viral RNA sequences from preserved autopsy tissues and from a frozen corpse were fully sequenced, and the virus was reconstructed by means of reverse genetics techniques. ${ }^{2}$

Autopsy studies and pathogenesis studies in experimental animals revealed that the 1918 virus differed significantly from other human and animal influenza viruses. It induced an aberrant immune response in part because of the inherent virulence of its $\mathrm{H} 1$ hemagglutinin (HA) protein, and it was highly copathogenic, producing virus-induced bacterial bronchopneumonias in association with commensal bacteria colonizing the nasopharynx (predominantly Streptococcus pneumoniae, S. pyogenes, and Staphylococcus aureus). ${ }^{2}$ 
The thousands of published autopsies revealed massive bacterial pneumonia in a bronchopneumonic pattern ${ }^{5}$ - that is, spreading outward in all directions from a damaged bronchial tree into the lung parenchyma - usually with interspersed areas of primary viral epithelial damage, diffuse alveolar damage, edema, hemorrhage, thrombi, and tissue repair. Even in areas of the lung where substantial bacterial damage had not yet occurred, alveoli were filled with neutrophils. Some victims died directly from hypoxemia due to widespread bronchopneumonia, often with terminal "heliotrope cyanosis," appearing clinically to suffocate or drown; others died of empyema or sepsis.

Of the many lessons learned from this deadly pandemic, four are of particular importance. First, the 1918 progenitor is very similar to contemporary circulating wild waterfowl influenza A viruses, and these will presumably continue to exist far into the future, capable of reemerging when human population immunity to H1N1 influenza A virus wanes. Moreover, 4 of the 15 other extant waterfowl HAs (H6, H7, H10, and H15) are, like the 1918 $\mathrm{H} 1$, highly pathogenic in mammals ${ }^{2}$ and could potentially cause similar extreme pandemic fatality. None of these pathogenic gene segments can be eradicated from nature, and some will inevitably appear in future pandemic viruses.

Second, we need to prioritize the optimization of our therapeutic and preventive armamentarium. We now have moderately efficacious antiviral drugs, effective antibiotics, and two pneumococcal vaccines. But we have no vaccines against most of the other bacteria that cause influenza co-pathogenic bronchopneumonias, such as $S$. pyogenes and Staph. aureus. In the 1918 pandemic, almost any bacterium colonizing the respiratory tract was a potential bronchopneumonic killer, including gram-negative bacteria such as - incredibly - meningococci in the absence of meningitis or meningococcemia. ${ }^{5}$ Preventing death from secondary bacterial pneumonia, which can develop so rapidly that systemic antibiotics are of little use, is a critical component of influenza prevention that has not been adequately addressed.

Third, the sudden onset and rapid progression of influenza bronchopneumonia in many patients in 1918 point to a critical need for better early indicators of influenza progression so that intensive treatment with systemic antibiotics can be initiated as early as possible. In 1918, progression to bronchopneumonia usually began several days after the onset of otherwise unremarkable symptomatic influenza; onset of lower respiratory involvement was typically subtle, with chest $\mathrm{x}$-rays often being normal and chest auscultation unremarkable right up to the beginning of a rapid downhill course, leaving a very narrow window for beginning lifesaving treatment. Reliable biomarkers of impending disease progression are urgently needed.

Fourth, the possibility that more than 2 million people could suddenly need intensive care with ventilatory support is a frightening reminder of the challenges of an influenza pandemic. Obviously, ICU capacity to address such a surge does not exist: although the contents of the U.S. Strategic National Stockpile are classified, it seems highly unlikely that enough ventilators, antibiotics, antivirals, and other supplies necessary to prevent mass deaths from a 1918-like pandemic would be available. The burden of preventing infection 
and transmission to others, and of medically managing care for millions of people with severe illnesses, would thus be placed squarely on public health and medical practitioners.

Such a 1918-like scenario is hard to imagine in a mobile country of nearly 330 million people. In 1918, about $98 \%$ of infected people had typical influenza-like illnesses without complications, no different in symptoms or severity from what we see today, and they recovered within a week or two. The other $2 \%$ experienced sudden onset of lower respiratory involvement after several days, which often progressed so rapidly that only early emergency treatment would be lifesaving today.

How could we identify the few patients who would have rapid progression among the many who would do well without special care? Epidemiologic information is helpful: in all influenza pandemics, including that in 1918, the groups at highest risk for severe or fatal outcomes have prominently included infants and toddlers, the elderly, pregnant women, and people of any age with chronic conditions such as respiratory or cardiac diseases, kidney diseases, or diabetes. But everyone else was at risk, too. In 1918, healthy 20-to-40-year-old adults had very high mortality (see photo), ${ }^{5}$ a still-unexplained phenomenon not seen before or since, which underlines influenza's capacity to surprise.

Practitioners would have to be aware, aggressive, and able to provide patients with immediate around-the-clock medical access. There are no easy solutions for containing such an explosive fatal pandemic. We need "universal" influenza vaccines that can broadly protect against any influenza A virus. But since the genetic and antigenic makeup of future influenza viruses cannot be predicted from the nearly infinite number of possibilities, developing a truly protective universal vaccine will be a significant challenge that has not yet been met. ${ }^{2}$

We hope that the 1918 pandemic's lessons will help us plan for future high-fatality pandemics. There is an enormous body of literature on the 1918 pandemic's clinical, pathologic, bacteriologic, surgical, radiologic, and epidemiologic features. The physicians and scientists who contributed to that literature hoped to guide future physicians. Sooner or later, millions of lives will depend on our learning from them and acting on their lessons.

\section{References}

1. Johnson NP, Mueller J. Updating the accounts: global mortality of the 1918-1920 "Spanish" influenza pandemic. Bull Hist Med 2002; 76: 105-15. [PubMed: 11875246]

2. Taubenberger JK, Kash JC, Morens DM. The 1918 influenza pandemic: 100 years of questions answered and unanswered. Sci Transl Med (in press).

3. Morens DM, Taubenberger JK. The mother of all pandemics is 100 years old (and going strong)! Am J Public Health 2018; 108: 1449-54. [PubMed: 30252528]

4. Jordan EO. Epidemic influenza: a survey. Chicago: American Medical Association, 1927.

5. Morens DM, Taubenberger JK, Fauci AS. Predominant role of bacterial pneumonia as a cause of death in pandemic influenza: implications for pandemic influenza preparedness. J Infect Dis 2008; 198: 962-70. [PubMed: 18710327] 
The possibility that more than 2 million people could suddenly need intensive care with ventilatory support is a frightening reminder of the challenges of an influenza pandemic. 


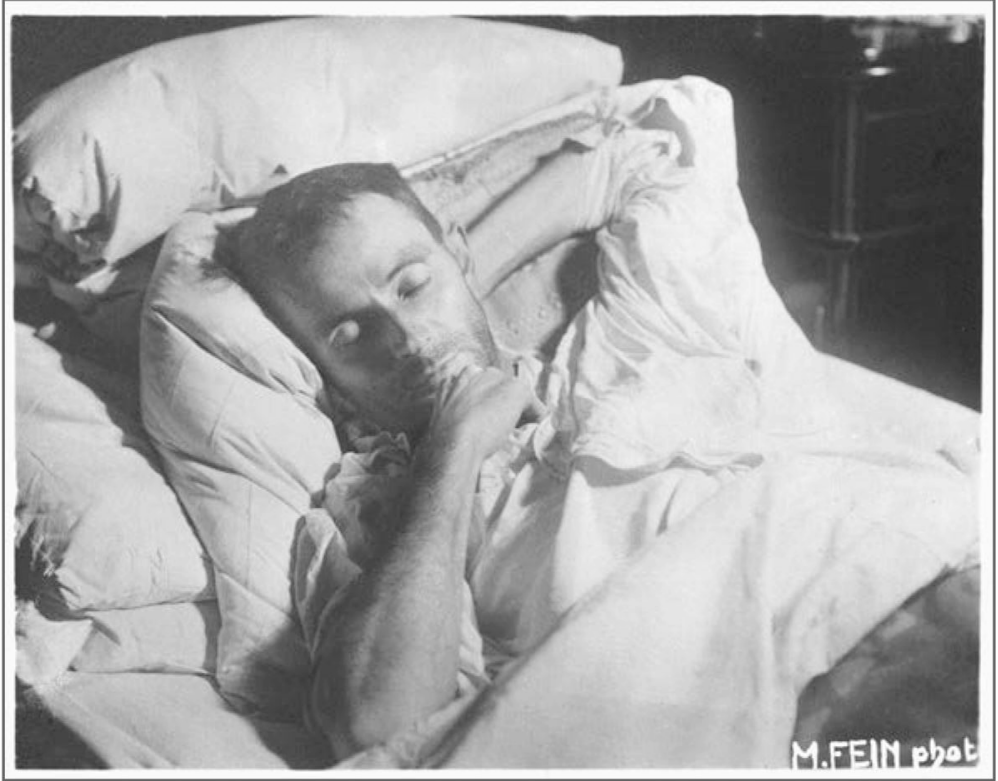

"Death Bed" Photograph of Renowned Viennese Painter Egon Schiele (1890-1918).

The 28-year-old Schiele and his wife, Edith Harms, who was 6 months pregnant, developed influenza in late October 1918; they died together. Many infected people in this age group died in the pandemic. ${ }^{3}$ During the week that Schiele and Harms lay dying, Austrian newspapers reported 2200 influenza-related deaths. Schiele's sketches of his dying wife, finished hours before his own death, were his last artistic works. 